\title{
Correction to: Volunteering and Self-Rated Health in Urban China: New Evidence from Analyses of Treatment-Effects Models
}

\author{
Zhongsheng $\mathrm{Wu}^{1}$ (D) $\cdot$ Angela Bies ${ }^{1}$ \\ Published online: 30 September 2020 \\ (C) The International Society for Quality-of-Life Studies (ISQOLS) and Springer Nature B.V. 2020
}

\section{Correction to: Applied Research in Quality of Life https://doi.org/10.1007/s11482-020-09868-5}

The original version of the article unfortunately contained an error.

Table 8 entries were corrected to reflect the correct values. The affected entries are highlighted as shown below.

Correct Version of Table 8

The online version of the original article can be found at https://doi.org/10.1007/s11482-020-09868-5

Zhongsheng Wu

zswu2015@umd.edu

1 School of Public Policy, University of Maryland, College Park, 2101 Van Munching Hall, College Park, MD 20742, USA 
Table 8 Summary and comparison of coefficients by different methods

\section{Wrong Version of Table 8}

Table 8 Summary and comparison of coefficients by different methods

\begin{tabular}{llllll}
\hline Method & Teffects & Psmatch2 & \multicolumn{2}{l}{ Normal regression } \\
\cline { 5 - 6 } & & PSM & NNM & Simple & Multiple \\
\hline Coefficient & & $0.131^{* * *}$ & $0.130^{*}$ & $0.169 * * *$ & $0.161^{* * * *}$ \\
Raw number & Treated & 1999 & 1999 & N/A & N/A \\
Matched number & Control & 3074 & 3074 & & \\
& Treated & 4967 & 4967 & & 4967 \\
\hline
\end{tabular}

\section{Correct Version of Table 8}

Table 8 Summary and Comparison of Coefficients by Different Methods

\begin{tabular}{cccccc}
\hline Method & Teffects & Psmatch2 & \multicolumn{2}{c}{ Normal Regression } \\
& PSM & NNM & simple & multiple \\
\hline Coefficient & $0.131^{* * *}$ & $0.130^{*}$ & $0.169^{* * *}$ & $0.161^{* * *}$ \\
\hline Raw & Treated & 1,918 & 1,918 & N/A & N/A \\
Number & Control & 3,049 & 3,049 & & \\
Matched & Treated & 4,967 & 4,967 & & \\
Number & Control & 4,967 & 4,967 & & \\
\hline \multicolumn{2}{c}{ Total Number in Estimation } & 4,967 & 4,967 & 4,967 & 4,967 \\
\hline
\end{tabular}

The numbers "1,999" and "3,074" in Table 8 of the published PDF version of my article need to be replaced with " 1,918 " and " 3,049 " respectively, as shown in the correct version of Table 8 above

The original article has been corrected.

Publisher's Note Springer Nature remains neutral with regard to jurisdictional claims in published maps and institutional affiliations. 